\title{
Atypical Lateral Periodontal Cyst- Case Report and Diagnosis
}

\author{
Dr. Gaurav Gupta ${ }^{*}$, Dr. D. K Gupta ${ }^{2}$, Dr. Neelja Gupta ${ }^{3}$
}

\author{
${ }^{1}$ MDS Associate Professor in Paediatric and Preventive Dentistry, Jaipur Dental College, Owner of Wisdom Dental Clinic, Jaipur, \\ India \\ ${ }^{2}$ MDS in Oral and Maxillofacial surgery, Senior Consultant at Wisdom Dental Clinic, Jaipur, India \\ ${ }^{3}$ BDS Cosmetic Dentist, Senior Consultant at Wisdom Dental Clinic, Jaipur, India
}

DOI: $\underline{10.36347 / \text { sjds.2022.v09i01.001 }}$

| Received: 27.11.2021 | Accepted: 03.01.2022 | Published: 07.01.2022

*Corresponding author: Dr. Gaurav Gupta

MDS Associate Professor in Paediatric and Preventive Dentistry, Jaipur Dental College, Owner of Wisdom Dental Clinic, Jaipur, India

\section{Abstract}

Lateral periodontal cyst is a rare developmental odontogenic type of cyst. It is being frequently diagnosed as an incidental radiographic finding, presenting as a well circumscribed round or tear shaped radiolucent area between the roots of vital teeth. It is often misdiagnosed as one of the lesion of endodontic origin. This case reports of a classical example of lateral periodontal cyst describing its clinical, radiological and histological features representing that the final diagnosis must be based on histopathological examination.

Keywords: Cyst, odontogenic cyst, periodontal cyst.

Copyright $(\mathcal{C} 2022$ The Author(s): This is an open-access article distributed under the terms of the Creative Commons Attribution 4.0 International License (CC BY-NC 4.0) which permits unrestricted use, distribution, and reproduction in any medium for non-commercial use provided the original author and source are credited.

\section{INTRODUCTION}

According to WHO odontogenic cysts are being classified as inflammatory and developmental based upon their epithelial lining, but lateral periodontal cyst (LPC) are non-keratinized and non-inflammatory developmental cysts which are located adjacent or lateral to the roots of vital teeth. These are most frequently found at the level of mandibular premolars but studies has also reported its occurrence in other areas too [1].

It is often being discovered during the radiographic examination, since pain as well as other clinical symptoms have seldom been reported in routine. Lateral periodontal cyst show well circumscribed round, ovoid or tear drop shaped radiolucent area, usually presenting with sclerotic margin. Mostly they are around $1 \mathrm{~cm}$ in diameter $[1,2]$.

Histologically, LPC presents a picture with distinct type of developmental cyst with very typical type of epithelial and connective tissue features. A correct diagnosis of lateral periodontal cyst is only possible based upon histopathological examination which later will decide its line of treatment that is to be undertaken. It is characterised by thin, non-keratinized epithelium usually having 1-5 layers, which resembles to reduced enamel epithelium, it exhibit plaque or focal thickening having clear glycogen containing epithelial cells while the connective tissue subjacent to epithelium shows a zone of hyalinization.[3]It is found to have differential diagnosis with endodontic as well as periodontal origin and other cysts having same groups $[1,2]$.

Considering the pathogenesis of LPC the gingival cyst of adult, botryoid odontogenic cyst and the glandular odontogenic cyst might be correlated [4]. Some of the authors reinforce that the gingival cyst of adult and LPC they both present with common histogenesis having same extraosseous and intra osseous features as based on their clinical as well as morphological similarities [5].

The origin of LPC still remains controversial with wide debate in the literature regarding its various etiopathological hypothesis [6]. LPC affects individuals mostly in between $5^{\text {th }}$ to $7^{\text {th }}$ decade of life. No racial or sex predilection is being yet reported [7]. Reports from various literature suggest a possible origin from either remnant of dental lamina, REE (reduced enamel epithelium) or rest of malassez [8, 9]. 
Conservative surgical enucleation of the lesion is usually done as a treatment of choice. Risk of reoccurrence of LPC is being estimated to be only $3-4 \%$ approx [10].

This case report reviews the classic case of diagnosis of lateral periodontal cyst which is located in anterior mandibular region representing brief literature review of its clinical, radiological as well as histopathological features.

\section{CASE REPORT}

A 50 year old male patient consulted at the clinic with chief complaint of swelling of gum in lower front tooth region. Upon clinical examination, a well circumscribed swelling measuring around $1 \mathrm{~cm}$ in diameter was found at the junction of buccal attached gingiva and free gingival margin in between the mandibular right canine and first premolar with gingival recession (tooth \# 43) (Figure 1a).

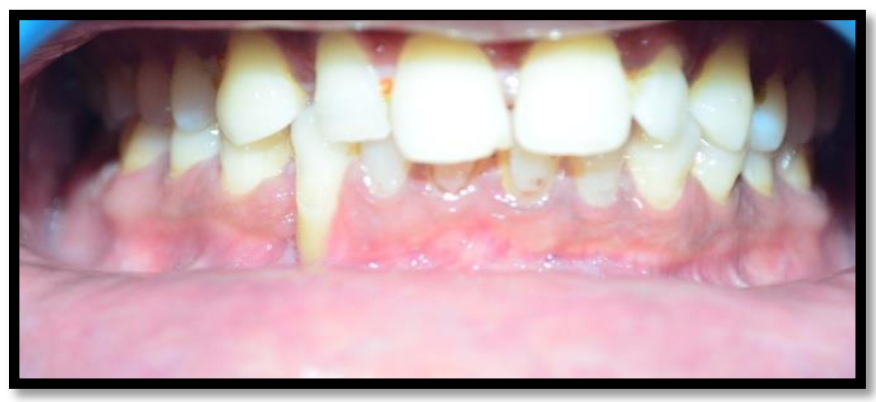

Figure 1a: Swelling in between canine and first premolar with gingival recession i.r.t tooth \# 43

Swelling was also found in lingual aspect too (Figure 1b).

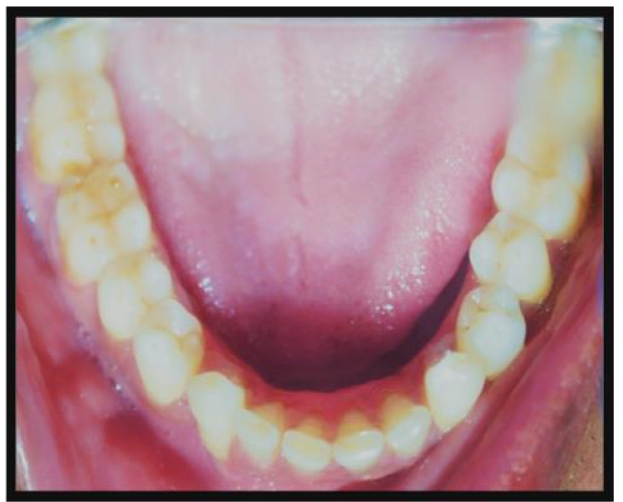

Figure 1b: Swelling in lingual aspect of affected region

Both teeth were vital and mobile. Extra oral examination did not show any visible asymmetry. While IOPA radiograph of the involved site revealed a radiolucent area of oval shape between canine and premolar roots (Figure 2).

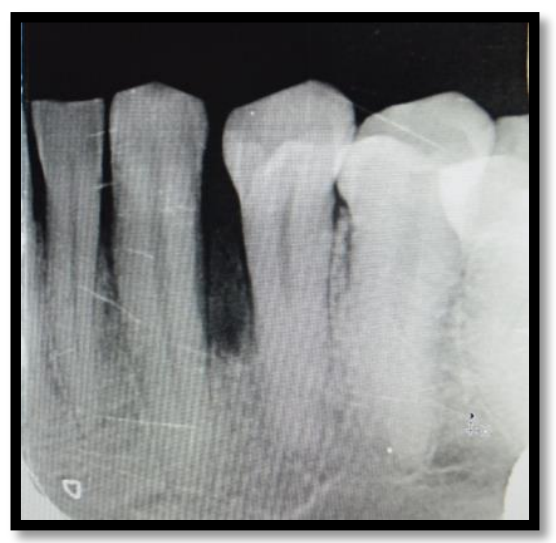

Figure 2: IOPA radiograph showing oval radiolucency in between canine and premolar 
CBCT image showed visible soft tissue shadow of well-defined growth in lingual aspect (Figure 3).

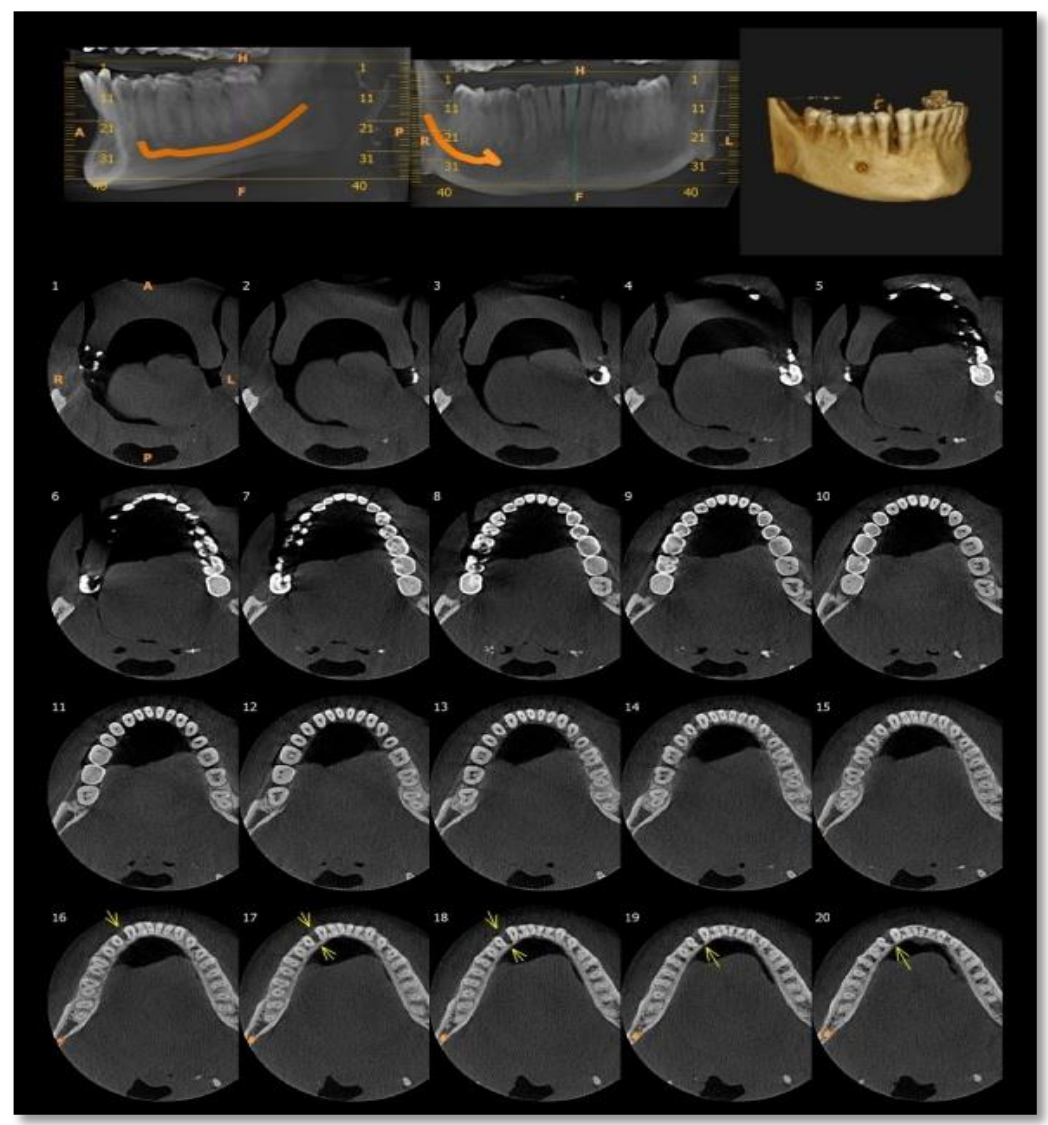

Figure 3: CBCT showing soft tissue growth shadow in lingual aspect of affected region

After receiving informed consent from the patient, treatment plan was made based upon the clinical and radiological findings a provisional diagnosis of lesion was made as lateral periodontal cyst.

Conservative surgical enucleation of the lesion was done. Sutures were placed along with periodontal dressing.
Post operative antibiotics and analgesics were prescribed to prevent any secondary infection. The post operative healing was uneventful.

The excised soft tissue specimen was then sent for histopathological examination which showed cyst lined by stratified squamous epithelium with inflammation giving final impression of benign inflammatory cyst (Figure 4).

\begin{tabular}{|l|l|}
\hline SLIDENO & A-40117 \\
SPECIMEN: & BIOPSY- LATERAL PERIODONTAL KERATOCYST \\
GROSS: & $\begin{array}{l}\text { The specimen comprises of three grey brown soft tissue pieces together } \\
\text { measuring } 0.8 \times 0.8 \mathrm{~cm} . \text { Entire taken for embedding. }\end{array}$ \\
MICROSCOPIC: & $\begin{array}{l}\text { Biopsy comprises of cyst lined by stratified squamous epithelium wall } \\
\text { shows inflammation. }\end{array}$ \\
\hline IMPRESSION: & $\begin{array}{l}\text { Benign inflammatory cyst. } \\
\text { No evidence of malignancy. }\end{array}$ \\
\hline
\end{tabular}

Figure 4: Histology report showing final impression as benign inflammatory cyst 
Follow up was done which did not reveal any clinical or radiographical evidence of its reoccurrence.

\section{DISCUSSION}

Standish and shafer in 1958 first reported LPC with series of five cases in mandibular region [11]. LPC is an unusual developmental odontogenic type of cyst which is often found associated with vital teeth and generally is found as asymptomatic unless and until it is secondarily infected. It is many a times reported in routine radiographic examination. Small gingival swelling is been occasionally reported $[6,8]$.

The most frequently affected site found is mandibular premolar and canine region or maxillary anterior region $[6,9,12]$. In our case too, cyst was found in mandibular canine premolar region.

Lateral periodontal cyst has its characteristic radiological feature as oval shape radiolucency along with sclerotic border between the crest and apex of the alveolar process. Similar radiographic images can be seen in interradicular radiolucencies such as cysts of pulpal origin, odontomas, tumours and jaw cysts [13]. LG Ramsssen and Mendes RA and Wan der waal in 2006 pointed that histological examination should be given more importance for the diagnosis of LPC than radiographical findings.[14] In our case IOPA radiograph showed typical presentation of lateral periodontal cyst with bone destruction. On the basis of clinical as well as radiological findings lateral periodontal cyst was provisionally diagnosed while histopathological report gave final impression of benign inflammatory cyst.

Botryoid odontogenic cyst shows similar HPE findings same as LPC, the only difference is that BOC has multilocular radiolucent areas. Some of the authors consider BOC as variant of LPC having higher chance of reoccurrence. Atilini and shear in 1992 gave classification of LPC into unicystic, polycystic and botryoid cyst variants. This classification is based upon hypothesis that all of the LPC lesions can progress to multicystic lesion [3]. Careful diagnosis should be made with the histopathological examination as some of the conditions are aggressive and have higher chances of reoccurrence with different treatment options too [15].

Literature explains that in all most all the cases of LPC, the associated teeth found are vital therefore extraction or any other endodontic treatment is not required. In LPC treatment should be surgical approach through enucleation and curettage of cystic lining so as to remove any remnants $[6,16]$. In our case we too approached for conservative surgery through curettage and removal of cystic lining of the affected region. Formosa Senande et al. reported that after lesion removal, the bone cavity fills up simultaneously with time.[17] Satisfactory healing was observed in our case both clinically as well as radiographically during its post operative evaluation. Patient follow up done for the evaluation of healing and also to check out for its reoccurrence.

The diagnosis of LPC must be restricted to cysts which are located to periodontal side. Differentiation between keratocystic odontogenic tumour, inflammatory cyst and the original lesion must be most importantly based upon clinical, radiological and histopathological findings [3, 7, 18]. LPC proportions does not increase more than $1 \mathrm{~cm}$ in size, while cyst of inflammatory origin tend to grow up. $[5,13,18]$ Our lesion was found to be $0.8^{*} 0.8 \mathrm{~cm}$.

In vital cases, LPC can be sometimes clinically confused with inflammatory processes when periodontal inflammation stimulates epithelium proliferation. Differential diagnosis must be established with radicular cysts, dentigerous cysts that is associated with non vital and impacted tooth respectively, while primordial cyst are located into mandibular ramus. Some authors also suggest that LPC can also cause isolated bone defects [19].

\section{CONCLUSION}

This case represents one of the typical case of lateral periodontal cyst with diagnostic dilemma. Considering LPC in differential diagnosis if, in the radiograph radiolucent area is found adjacent to the mandibular canine and premolar. The histopathological examination is must in order to confirm the diagnosis, thus making conservative surgical approach as the treatment of choice. By reporting this rare case, we would emphasise the oral clinicians that there are wide range of odontogenic cysts as well as anatomic structures that are found associated with canine and premolar in mandible of which lateral periodontal cyst have rare chance of possibility.

\section{REFERENCES}

1. Krier, P. W. (1980, May). Lateral periodontal cyst. Oral Surg Oral Med Oral Pathol, 49(5), 475.

2. Nikitakis, N. G., Brooks, J. K., Melakopoulos, I., Younis, R. H., Scheper, M. A., Pitts, M. A., ... \& Sklavounou, A. (2010). Lateral periodontal cysts arising in periapical sites: a report of two cases. Journal of endodontics, 36(10), 1707-1711.

3. Altini, M., \& Shear, M. (1992). The lateral periodontal cyst: an update. Journal of oral pathology \& medicine, 21(6), 245-250.

4. Shear, M. (1994). Developmental odontogenic cysts. An update 1. Journal of oral pathology \& medicine, 23(1), 1-11.

5. Wysocki, G. P., Brannon, R. B., Gardner, D. G., \& Sapp, P. (1980). Histogenesis of the lateral periodontal cyst and the gingival cyst of the adult. Oral Surgery, Oral Medicine, Oral Pathology, 50(4), 327-334. 
6. Friedrich, R. E., Scheuer, H. A., \& Zustin, J. (2014). Lateral periodontal cyst. in vivo, 28(4), 595-598.

7. Cohen, D. A., Neville, B. W., Damm, D. D., \& White, D. K. (1984). The lateral periodontal cyst: a report of 37 cases. Journal of periodontology, 55(4), 230-234.

8. de Carvalho, L. F., Lima, C. F., Cabral, L. A., Brandao, A. A., \& Almeida, J. D. (2010). Lateral periodontal cyst: a case report and literature review. J Oral Maxilofac Res, 1(4), p. e5.

9. Bilodeau, E. A., \& Collins, B. M. (2017). Odontogenic cysts and neoplasms. Surgical pathology clinics, 10(1), 177-222.

10. Siponen, M., Neville, B. W., Damm, D. D., \& Allen, C. M. (2011). Multifocal lateral periodontal cysts: a report of 4 cases and review of the literature. Oral Surgery, Oral Medicine, Oral Pathology, Oral Radiology, and Endodontology, 111(2), 225-233.

11. Standish, S. M., \& Shafer, W. G. (1958). The lateral periodontal cyst. J Periodontol, 29(1), pp. 27-33.

12. Chrcanovic, B. R., \& Gomez, R. S. (2019). Gingival cyst of the adult, lateral periodontal cyst, and botryoid odontogenic cyst: an updated systematic review. Oral diseases, 25(1), 26-33.

13. Rasmusson, L. G., Magnusson, B. C., \& Borrman, H. (1991). The lateral periodontal cyst. A histopathological and radiographic study of 32 cases. British Journal of Oral and Maxillofacial Surgery, 29(1), 54-57.

14. Amaral Mendes, R., \& van der Waal, I. (2006). An unusual clinicoradiographic presentation of a lateral periodontal cyst: Report of two cases. Medicina Oral, Patología Oral y Cirugía Bucal (Internet), 11(2), 185-187.

15. de Andrade, M., Silva, A. P. P., de Moraes RamosPerez, F. M., Silva-Sousa, Y. T. C., \& da Cruz Perez, D. E. (2012). Lateral periodontal cyst: report of case and review of the literature. Oral and maxillofacial surgery, 16(1), 83-87.

16. Agha, R. A., Borrelli, M. R., Farwana, R., Koshy, K., Fowler, A. J., Orgill, D. P., ... \& Kasi, V. (2018). The SCARE 2018 statement: updating consensus Surgical CAse REport (SCARE) guidelines. International Journal of Surgery, 60, 132-136.

17. Formoso Senande, M. F., Barbosa de Figueiredo, R. P., Berini Aytés, L., \& Gay Escoda, C. (2008). Lateral periodontal cysts: A retrospective study of 11 cases. Medicina Oral, Patología Oral y Cirugia Bucal, 2008, vol. 13, num. 5, p. 313-317.

18. Eliasson, S., Isacsson, G., \& Köndell, P. A. (1989). Lateral periodontal cysts: clinical, radiographical and histopathological findings. International journal of oral and maxillofacial surgery, 18(4), 191-193.

19. Filipowicz, F. J., \& Page, D. G. (1982). The lateral periodontal cyst and isolated periodontal defects. Journal of periodontology, 53(3), 145-151. 